\title{
Improving the system of selection and seed production of soft wheat for irrigated lands of Uzbekistan
}

\author{
Umida Karshieva ${ }^{1}$ \\ ${ }^{1}$ PhD, Samarkand Veterinary Medical Institute, Department of Genetics, Breeding and Seed, \\ Samarkand, Uzbekistan \\ Email:yalgashev@gmail.com
}

\begin{abstract}
The paper is dedicated to creating the source material and a new variety of winter soft wheat, resistant to adverse environmental factors with high rates of economically valuable traits.
\end{abstract}

Keywords: initial material, selection, shear-wheel wheat, winter wheat, early ripeness, creating varieties.

\section{INTRODUCTION}

Wheat (Triticum aestivum L.) is the main food crop, the production and demand of which is growing in parallel.

According to the forecasts of the international organization FAO, the production of wheat in 2019 amounted to 766 million tons, and the global demand for wheat is 761.5 million tons. Lately, global climate change has a strong negative impact on productivity, the complete formation and quality of wheat grains. Special attention is paid to breeding to create high-yielding wheat varieties with high quality indicators that are resistant to diseases and pests, lodging and adverse environmental factors in countries growing wheat.

For economic sovereignty the most complete realization of the interests of people. Ensuring their social protection by the Government of Uzbekistan, a course was chosen to sharply increase its own production of food grain. One of the main factors for solving this problem is the continuous improvement of varieties of crops, including wheat. In recent years, the creation and introduction of short-stemmed varieties in a number of countries has allowed the most successful solution to the problem of increasing wheat grain yield. These circumstances raise the question for breeders about the need for more detailed research on a short-stemmed breeding strategy, identifying the effects of the Rht genes on some selectively valuable traits in order to create highly productive genotypes with an optimal height and a successful combination of valuable traits.

The aim of the research is to create the source material and a new variety of winter soft wheat that are resistant to adverse environmental factors (heat, drought, salinization of the soil, diseases), which have high rates of economically valuable characteristics.

The objectives of the research are as follows:

- determination of morphological, biological and economically valuable traits and properties of varieties of common wheat of various geographical origin;

- $\quad$ selection of varieties of soft wheat with economically valuable traits by the length of the growing season, morphological, biological and economically valuable traits;

- $\quad$ hybridization of varieties of common wheat with local varieties, determination of the degree of heritability and correlation of signs and properties of the obtained hybrids, as well as the use of hybrid lines in the breeding process;

- creation of a high-yielding source material and variety with resistance to adverse environmental factors, a high yield and its quality based on the assessment and selection of varieties of soft wheat;

- $\quad$ according to the most important biological and economically valuable traits and to select the best of them for use in breeding short-stemmed varieties of wheat of the intensive type for irrigated conditions of 
the Zarafshan valley of Uzbekistan;

- $\quad$ revealing the nature of inheritance, the heritability and correlation of quantitative traits in plants of wheat cultivar F1-F3 obtained by crossbreeding with various donors of short-stemmed plants;

- determining the effect of genes that determine short-stemming, on breeding valuable traits of common wheat and the direction of their use;

- $\quad$ giving a selection assessment of the lines created on the basis of crossbreeding with different donors of short stems and recommend them for further breeding work.

- The object of research was 1140 samples of soft wheat obtained from the world collection of the Plant Research Institute and the International Center for Agricultural Research in the Dry Areas, the International Maize and Wheat Improvement Center (CIMMYT, Mexico), and the Gallaral branch of the Andijan Scientific Research Institute of Grain and leguminous crops on irrigated lands.

The subject of research is germination, growth and development, resistance to adverse abiotic and biotic environmental factors, lodging, heritability of morphophysiological and economically valuable indicators, correlative relationship, yield and grain quality of varieties and samples of winter soft wheat.

Assessment by morphological and biometric indicators of varieties of soft wheat was carried out according to the method of the "International Classifier of CMEA of the genus Triticum L." (L., 1984), developed according to the genus Triticum L., as well as according to the Peterson and Manners scale developed by the ICARDA International Scientific Center (1996) Assessment of resistance to rust diseases in the field was carried out using the Modified Cobb scale in percent $(0-100 \%$ Peterson and others, 1948). The degree of heat resistance was determined according to the method of N. Kozhushko, the accuracy and reliability of the obtained experimental data were subjected to mathematical and statistical processing according to the methods specified in the book of B. A. Dospekhov "Methods of field experience" (1985).

The scientific novelty of research is as follows:

- $\quad$ For the first time, early ripening, resistant to salinization, heat and drought, samples were selected from soft wheat varieties of various geographical origin and evaluated according to their economically valuable traits and properties;

- $\quad$ the presence of a strong positive correlation relationship $(r=0.75-0.80)$ between the mass of 1000 pieces of grain and lodging, a negative correlation with the height of the plant, a positive correlation with the length of the spike and the number of grains in one spike $(r=0.24-0,85)$;

- $\quad$ it was revealed that the existence of right-sided transgression along the length of the ear, the number of grains in one ear and the mass of 1000 pieces of grains obtained with the participation of local and foreign variety varieties of hybrids, increases the yield of plants with high rates in high generations;

- the source material of the variety samples and a new variety of soft wheat "Kipchoksuv" were created as a result of selection according to quantitative characteristics, ensuring yields, possessing a complex of economically valuable characteristics.

The practical results of the study are as follows:

- "Kipchoksuv" soft winter wheat variety was developed for irrigated lands based on research results and transferred to the Center for Testing Agricultural Varieties;

- $\quad$ varietal samples of winter soft wheat, which have economically valuable traits, are recommended to breeding institutions as a starting material for creating new varieties..

\section{MATERIALS AND METHODS}

Early ripening varieties in the conditions of Uzbekistan go away from drought, fungal diseases, early freeing the land that will allow to get 2-3 crop production in one year. Growing season. Early ripening varieties in the conditions of Uzbekistan go away from drought, fungal diseases, early freeing the land that will allow to get 2-3 crop production in one year. The results of our studies showed that the duration of the growing season was characterized by variability (214-235 days).

With a decrease in plant height, the pattern of earlier ripening was traced. The earliest samples of wheat were identified in the group of low-growing varieties. Great value as an initial material for selection for precocity in the irrigated conditions of Uzbekistan are early maturing samples Dubr 232 (Peru), Seri 21 (Turkey), K52103 (Ecuador), K23014 (Syria), VDME-9 (Turkey), K-5 8643 (Norway), K 62154 (Japan), K58741 (India), K60273 (Mexico), 7316 (Afghanistan). Combining precocity with other biological and economically valuable traits that we included in the breeding program and based on them 
created the original breeding material.

In Uzbekistan, for some years, air temperature drops to $-26.3^{\circ}-34.60^{\circ} \mathrm{C}$, which leads to the death of crops and grain losses. The research results indicate a wide range of winter hardiness studied 1140 wheat samples from 79.8\% (K-8960 Canada), up to 90.8\% (K-52627 USA), (K-2527 Australia), CH-75600 (Switzerland). Of particular note is the K-52627 USA variety specimen combining high winter hardiness with high yielding capacity $(854 \mathrm{~g} / \mathrm{m} 2)$. An analysis of experimental data on the winter hardiness of short-stem donors showed that samples originating from the USA, Australia, Switzerland in Uzbekistan showed poor winter hardiness.

\section{RESULTS}

The most reliable and cost-effective means of preventing lodging of bread is the use of shortstalked varieties of wheatgrass with mechanically elastic straw. An analysis of the experimental data on resistance to lodging of short-stemmed donors with Rht genes gives grounds to conclude that the donor carrying three short-stemmed genes showed high abstraction.

Of particular note are short-stem donors with the genes Rht 1, Rht 2, Rht 5, Rht 6, Rht 11, Rht 13. Particularly noteworthy are the samples of wheatgrass combining resistance to lodging with high productivity Agra (Mexico), 9809/15 (CIT), 83/108 (CIMMYT), FRL-2004 (Turkey), CWI64790 (Mexico), N92L192 (USA).

Yellow and brown rust, powdery mildew, dusty and hard smut cause the greatest harm to obtaining high yields of wheat of wheat. The results of a study on resistance to short-stemmed donor diseases with Rht genes to the above diseases showed that of the 35 short-stemmed donors, the highest resistance was observed in forms with Rht 1 and Rht 2 genes. Mexico, USA, Turkey.

The mass of grain per unit area is the main criterion for the effectiveness of breeding work. The obtained data on grain yield showed a significant variation from 272 ZHOHNJ (China) to 951 -g / m2 (K 5121 Bulgaria). On average, the highest grain yield (K 5121, Bulgaria), 9821/16 (CIT), 9809/15 (CIT), ATAU85 (Turkey). K60607 (Australia) was obtained by us in the group according to the height of plants of short-stemmed $(86-105 \mathrm{~cm})$ line varieties.

\section{CONCLUSION}

Based on the experiments, the following conclusions can be drawn. A long study of the source material of winter soft millet made it possible to identify the best samples under local conditions by a set of economically valuable traits. For the crossbreeding of early ripening varieties, it is necessary to use the varieties Dubr 232 (Peru), Seri 21 (Turkey), K 52103 (Ecuador), K 23014 (Syria), VDME-9 (Turkey), K58643 (Norway), K 62154 (Japan), K 58741 (India), K 60273 (Mexico), K 7316 (Afghanistan).

Agre (Mexico), 9809/15 (SIT), 83/108 (CIMMYT), FRL-2004 (Turkey), CW I64790 (Mexico), N92 L1 92 (USA) were isolated and recommended for crossbreeding.

A valuable source material for breeding for disease resistance is K 555682 (India), K 40700 (France), K 60273 (Mexico), K 62080 (Peru). On average, the highest grain yield (K 5121, Bulgaria). 9821/16 (CIT), 9809/15 (CIT), ATAU 85 (Turkey). To 60607 (Australia), we obtained in the group according to the height of plants of short-stemmed $(86-105 \mathrm{~cm})$ line varieties.

\section{REFERENCES}

1. Armor, B.A., 1985: Methods of field experience (with the fundamentals of statistical processing of the results of research) / 5th ed. Revised. and ext. - M: Agropromizdat, 1985. - 351.

2. Udachin R.A., Shahmedov I., 1984: Wheat in Central Asia. - Tashkent, Uzbekistan Central Asian branch of the Union of Plant Research Institute. Vavilov (Academy of Agricultural Sciences). - 1984.

3. Khodjakullov T. H., Hahlov A., 1991: Results of breeding wheat for conditions of Uzbekistan. News from the X-science, 1991, issue 5, 143-146. 